Review

\title{
Nocardiosis in Kidney Disease Patients under Immunosuppressive Therapy: Case Report and Literature Review
}

\author{
Tao Wang ${ }^{1 * 凶}$, Yun Jia ${ }^{2 *}$, Bao Chu ${ }^{3}$, HongTao Liu ${ }^{4}$, XiaoLi Dong 3 , Yan Zhang 5 \\ 1. Department of Science and Education, HeBei General Hospital, No.348 West HePing Boulevard, ShijiaZhuang 050051, P.R. China. \\ 2. Department of Clinical Immunology, Xijing Hospital, the Fourth Military Medical University, No.127 West Changle Road, Xi'an 710032, P.R. China. \\ 3. Department of Neurology, No.348 West HePing Boulevard, ShijiaZhuang 050051, P.R. China. \\ 4. Department of Pharmacology, No.348 West HePing Boulevard, ShiJiaZhuang 050051, P.R. China. \\ 5. Department of Dermatology, the 4th Affiliated Hospital of HeBei Medical University, No.12 JianKang Road, ShiJiaZhuang 050011, P.R. China. \\ *Equal Contribution as first author
}

$\square$ Corresponding author: Dr. Tao Wang, Department of Science and Education, HeBei General Hospital, No.348 West HePing Boulevard, ShiJiaZhuang 050051, China. Tel: +86-18632191726; E-mail: nephrology2009@hotmail.com

(C) Ivyspring International Publisher. This is an open access article distributed under the terms of the Creative Commons Attribution (CC BY-NC) license (https://creativecommons.org/licenses/by-nc/4.0/). See http://ivyspring.com/terms for full terms and conditions.

Received: 2018.12.20; Accepted: 2019.05.05; Published: 2019.06.02

\begin{abstract}
The increased use of novel and powerful immunosuppressive drugs in kidney diseases may concomitantly expose the patients to higher risk of opportunistic infections, some of which still remain underdiagnosed thus mishandled. As such, we recently had a less prepared encounter of pulmonary nocardial infection in an ANCA-associated renal vasculitis patient under steroid therapy. Despite the use of broad-spectrum antimicrobials including micafungin, the infection was still unbridled and eventually culminated in lethal brain abscess.

We thus chose to renew the knowledge of the clinical features, imaging manifestations, differential diagnosis, specific laboratory tests and unique treatment about this rare infection in kidney diseases patients under immunosuppressive therapy. In addition, CT images of easily confused pulmonary lesions superimposed on kidney diseases were also retrieved from our depository. Moreover, impaired renal function as a risk factor for infection and pharmacological options for the treatment were also focused.

By sharing our hard-learnt experience and reviewing the literatures, our report may contribute to the awareness among the clinicians in general and nephrologists in particular of this rare disease in susceptible patients and facilitate a swift thus life-saving treatment.

Key words: kidney diseases, immunosuppression, opportunistic infection, nocardiosis,
trimethoprim/sulfamethoxazole
\end{abstract}

\section{Introduction}

Nephrologists are now facing an increased use of novel immunosuppressive agents against a broad-spectrum of kidney diseases or situations including but not limited to renal vasculitis, nephrotic syndrome, lupus nephritis and monoclonal gammopathy of renal significance $[1,2,3]$. Besides the well-defined actions of the calcineurin inhibitors [4], they may act on the CD28/CTLA-4-B7 pathway (Belatacept) [5], which are basically the award-winning materials of the latest Nobel Prize. Alternatively, the therapeutic mechanisms of these agents may respectively target the differentiation antigen CD52 (Alemtuzumab), CD25 (Basiliximab) and CD20 (Rituximab) located on the surface of T- or B-lymphocytes [4]. In concerted action, simultaneous use of corticosteroids may lead to a reduction of neutrophil chemotaxis, $\mathrm{T}$ cell activation and proliferation, and macrophage function. Not 
unexpectedly, these powerful immunosuppressants may also expose the patients to increased risk of serious infections [5,6] including the opportunistic one caused by Nocardia spp [7].

The genus Nocardia is a member of the mycobacteriaceae family, which is ubiquitous in nature but normally not present in human [8]. The namesake nocardiosis is a rare infection usually seen in susceptible patients with underlying chronic diseases or immunosuppression of endogenous or iatrogenic origin [9]. In sporadic cases, pulmonary nocardial infection or cerebral abscess was encountered in patient treated for nephrotic syndrome, systemic lupus erythematosus, anti-neutrophil cytoplastic antibody (ANCA)associated renal vasculitis or renal transplant (Table 1, with references 10-19). Clinical recognition of this disease remains difficult due to its low incidence and lack of pathognomic symptoms. Reportedly, the median time interval between onset of symptoms and diagnosis was 30 days [20]. In most cases, late diagnosis is related to mortality in addition to the severity of the underlying disease and an advanced or disseminated form of nocardial infection [21,22]. Consistent with our experience, delayed diagnosis may also be responsible for some likely remedial lethality [23].

This article therefore presented a typical case and reviewed the clinical features, imaging manifestations, differential diagnosis, specific laboratory tests and unique treatment of this rare infection, especially with substantial attention to the complete evolution of pulmonary nocardial infection with ensuing lethal brain abscess from our hard-learnt experience. The study had acquired proper institutional approval and necessary consent from the participants.

\section{Case Presentation}

The index case was a 53-year old woman with acute renal failure, who had elevated serum creatinine of $\quad 380.7 \mu \mathrm{mol} / \mathrm{L} \quad$ (reference 44.2-132.6 $\mu \mathrm{mol} / \mathrm{L}$ ), positive ANCA against myeoperoxidase and biopsyconfirmed type III crescentic glomerulonephritis. Besides four sessions of plasmapheresis, she was treated for ANCA-associated renal vasculitis with daily intravenous mythelprednisolone of $320 \mathrm{mg}$ for three consecutive days and $40 \mathrm{mg}$ thereafter. Free of pulmonary infection (PI) (Figure 1), the patient was discharged one month later with a daily oral dose of 40mg mythelprednisolone.

Table 1. Nocardial infection in patients with kidney disease having immunosuppressive therapy.

\begin{tabular}{|c|c|c|c|c|c|c|}
\hline & Type of kidney disease & Immunosuppressive agents & Clinical features & Treatment (antibiotics) & Outcome & Reference \\
\hline 1 & nephrotic syndrome & methylprednisolone & $\begin{array}{l}\text { subcutaneous abscesses and } \\
\text { pulmonary infection }\end{array}$ & $\begin{array}{l}\text { TMP-SMX and } \\
\text { cefatriaxone }\end{array}$ & recovery & [10] \\
\hline 2 & nephrotic syndrome & MMF and prednisone & $\begin{array}{l}\text { pulmonary and intramuscular } \\
\text { abscesses }\end{array}$ & $\begin{array}{l}\text { imipenem and } \\
\text { levofloxacin }\end{array}$ & recovery & [11] \\
\hline 3 & nephrotic syndrome & $\begin{array}{l}\text { cyclophosphamide and } \\
\text { prednisolone }\end{array}$ & $\begin{array}{l}\text { pulmonary infection and } \\
\text { cerebral abscess }\end{array}$ & TMP-SMX & recovery & [12] \\
\hline 4 & lupus nephritis & $\begin{array}{l}\text { cyclophosphamide and } \\
\text { methylprednisolone }\end{array}$ & pleural effusion & TMP-SMX & recovery & [13] \\
\hline 5 & lupus nephritis & cyclophosphamide & $\begin{array}{l}\text { pulmonary infection and } \\
\text { occipital abscess }\end{array}$ & $\begin{array}{l}\text { cotrimoxazole and } \\
\text { cefixime }\end{array}$ & recovery & {$[14]$} \\
\hline 6 & lupus nephritis & $\begin{array}{l}\text { azathioprine and } \\
\text { prednisolone }\end{array}$ & $\begin{array}{l}\text { subcutaneous and brain } \\
\text { abscesses }\end{array}$ & $\begin{array}{l}\text { TMP-SMX and } \\
\text { cefatriaxone }\end{array}$ & recovery & [15] \\
\hline 7 & systemic vasculitis & MMF and prednisolone & cerebral abscesses & meropenem & death & [16] \\
\hline 8 & renal transplant & $\begin{array}{l}\text { cyclosporine, azathioprine } \\
\text { and prednisolone }\end{array}$ & cerebral abscess & TMP-SMX & recovery & {$[17]$} \\
\hline 9 & renal transplant & tacrolimus and $\mathrm{MMF}$ & cerebral abscess & $\begin{array}{l}\text { imipenem and } \\
\text { levofloxacin }\end{array}$ & recovery & [18] \\
\hline 10 & renal transplant & $\begin{array}{l}\text { cyclosporine, MMF and } \\
\text { prednisolone }\end{array}$ & pulmonary infection & cefatriaxone & recovery & [19] \\
\hline
\end{tabular}

TMP-SMX: trimethoprim-sulfamethoxazole. MMF: mycophenolate mofetil. 

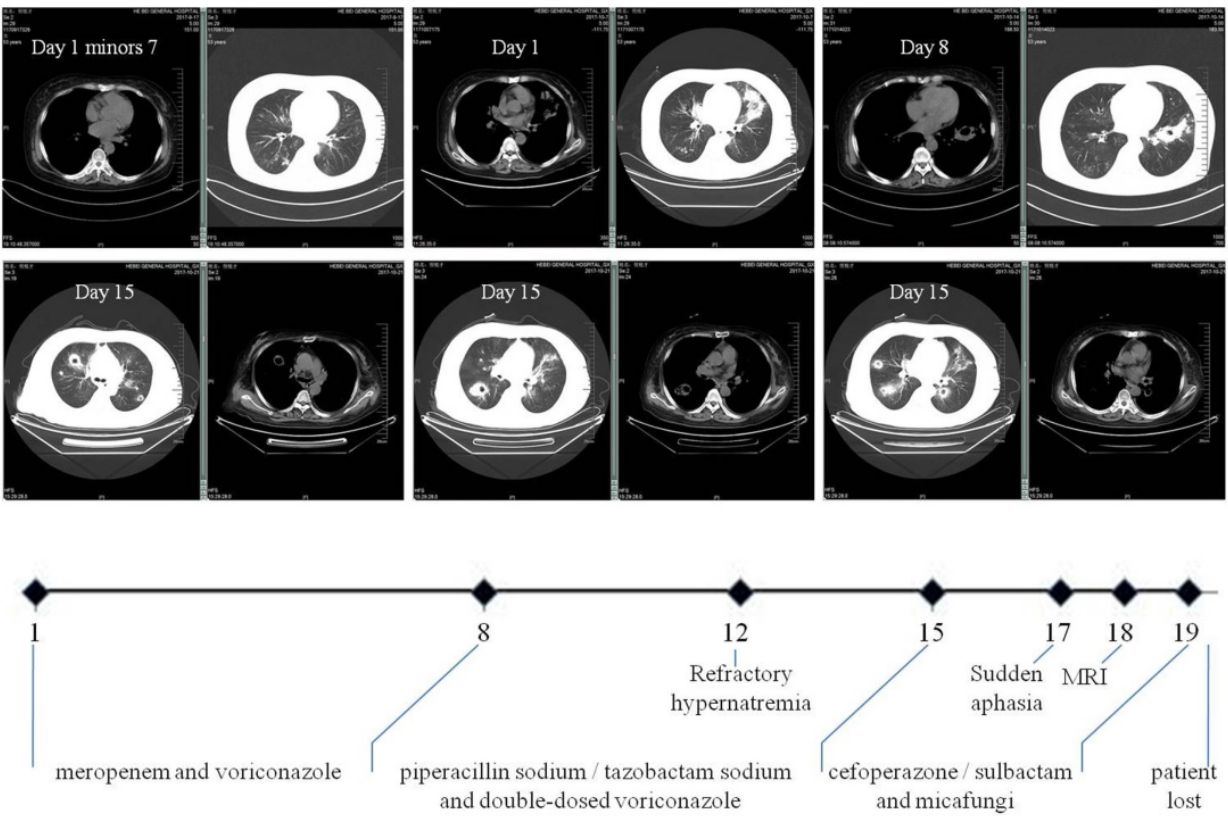

Figure 1. Clinical course of our case. It schematically recorded the selection of antibiotics according to the dynamic changes of CT images and the accompanying complications. In particular, multiple polysized pulmonary nodules with cavitation at different levels were highlighted (both parenchymal and mediastinal windows). The numbers on the $X$ axis denote the day from the admission (Day 1) to the loss of patient (Day 20).

Readmission occurred seven days post hoc due to fever $\left(38.6^{\circ} \mathrm{C}\right)$ and hemoptysis. CT scan on admission (Day 1) found PI with cavitation. Laboratory tests showed WBC count $20.3 \times 10^{9} / \mathrm{L}$ with $96.9 \%$ neutrophils, T-lymphocyte count 102/uL $(690-1760 / \mathrm{uL})$, hemoglobin $110 \mathrm{~g} / \mathrm{L} \quad(130-150 \mathrm{~g} / \mathrm{L})$, platelet $170 \times 10^{9} / \mathrm{L} \quad\left(100-300 \times 10^{9} / \mathrm{L}\right)$, C-reaction protein $185.2 \mathrm{mg} / \mathrm{L}(<10 \mathrm{mg} / \mathrm{L})$, calcitonin $1.6 \mathrm{ng} / \mathrm{mL}$ $(<0.05 \mathrm{ng} / \mathrm{mL}),(1,3)-\beta$ glucan $D$ detection test (G-test) $67.8 \mathrm{pg} / \mathrm{mL} \quad(<10 \mathrm{pg} / \mathrm{mL})$, serum creatinine 300.0umol/L, normal coagulation function including D-dimer and negative ANCA. Aerobic sputum but not blood cultures produced aeruginosa. She was immediately given intravenous broad-spectrum antibiotics with dose and form respectively determined by creatinine clearance and CT findings (Figure 1): meropenem and voriconazole (Day 1 to 8 ), piperacillin sodium/tazobactam sodium and voriconazole with double-dose (Day 9 to 14), cefoperazone/sulbactam and micafungi (Day 15 to 19). The use of steroid was continued but reduced to half-dose two days after admission. Meanwhile, recurrent hypernatremia emerged $(150-170 \mathrm{mmol} / \mathrm{L})$ which was only remedial to blood purification. There was sudden aphasia and right hemiparesis, prompting the collection of blood and sputum from deep trachea for specific microbial tests by our pharmacological center, which is a reliable and sophisticated research institution $[24,25]$. In short notice thereafter, brain abscess was detected by MRI (Figure 2). The patient's condition further worsened and her vitals were no longer sustainable (Day 20).
After that, growth of Nocardia asteroids from the said sputum was found on the Loewenstein-Jensen media and subsequently confirmed by the $16 \mathrm{~S}$ rDNA sequence analysis [26].

\section{Discussion}

\section{Pulmonary nocardial infection}

The body site most frequently involved was the lung accounting for $70 \%$ of the infection, followed by the skin and the brain [27]. Pulmonary involvement may manifest fever, cough and hemoptysis, with pleomorphic radiographical findings of infiltration $(62.6 \%)$, multiple nodules $(31.3 \%)$ and cavitations (18.8\%) [20] (Figure 1). Accordingly, the main differential diagnosis includes invasive fungal disease, Wegener's granulomatosis, malignancy, alveolar hemorrhage in ANCA-associated vasculitis and tuberculosis. As priori, invasive pulmonary aspergillosis may demonstrate the characteristic halo sign on CT scan (Figure $3 \mathrm{~A}$ and B) and a definite diagnosis is supposedly possible in the later course of infection (clinical symptoms and signs $>10$ days) with elevation of the G-test [28]. By comparison, pulmonary nodules in Wegener's granulomatosis were usually well demarcated and distributed mainly in the peripheral zone on CT scan (Figure 3C and D) [29]. Of note, increased disease activity is almost inevitably accompanied by elevated ANCA titer (predominantly anti-proteinase 3) and aggravated target organ damage. In clinical practice, however, these diagnostic clues may be perplexedly blurred in such a way that the above lesions sometimes bear 
close resemblance (Figure 3E and F). Nonetheless, we believed that the solution to this dilemma depends on the simultaneous recognition of risk factors, monitoring for clinical symptoms and attention to accessory test results [30]. At last, CT images of alveolar hemorrhage in ANCA-associated vasculitis and lung cancer with multiple intrapulmonary metastases were also available (Figure 3G and H).

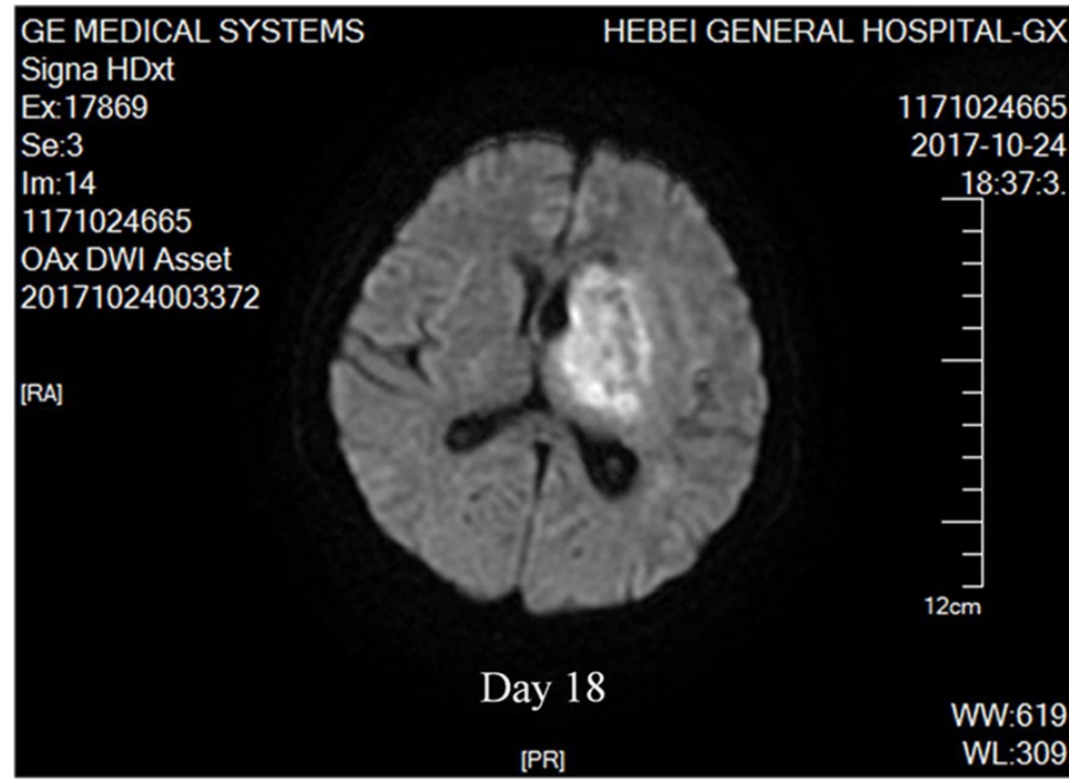

Figure 2. Nocardial brain abscess. On the 18th day after admission, diffusion weighed axial MRI of our patient detected brain abscesses. The lesion had mixed signal intensity with hypointense capsule surrounded by high signal edema zone.
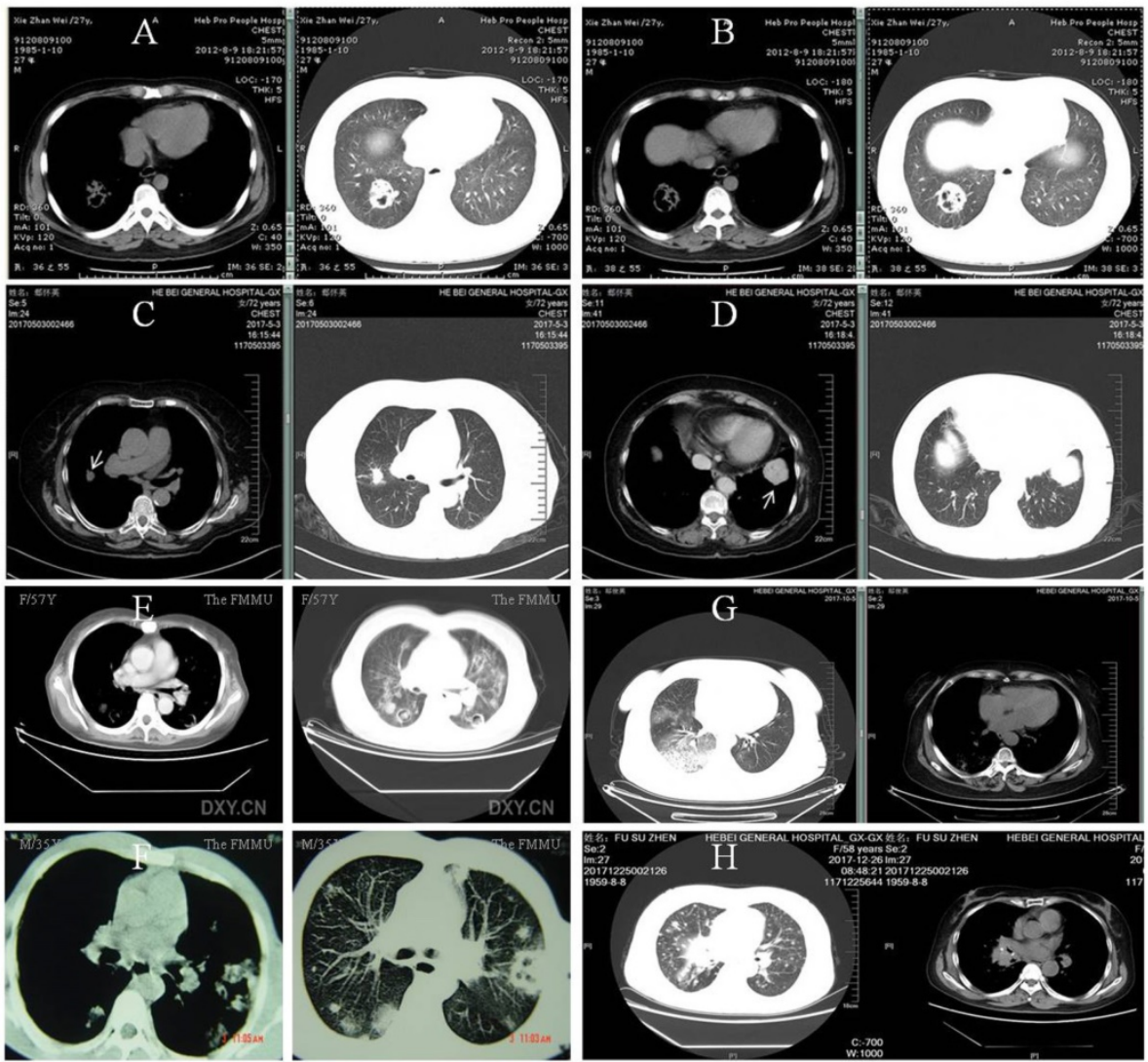

Figure 3. Pulmonary invasive fungi infection, Wegener's granulomatosis and the like. A and B: Pulmonary aspergillosis in a patient of lupus nephritis receiving cyclophosphamide and steroid. He had a G-test of $362 \mathrm{pg} / \mathrm{mL}$ (reference, <10pg/mL) with etiological evidence. C and D: Multiple nodules (arrows) in biopsy-proven Wegener's granulomatosis. The patient also had positive ANCA against the proteinase 3. E and F: complicated pulmonary invasive fungi infection and Wegener's granulomatosis, respectively. Clinically confirmed pulmonary aspergillosis in a 57-year female treated for monoclonal gammopathy of renal significance (E) and biopsy-proven Wegener's granulomatosis in a 35-year male (F). G and H: pulmonary vasculitis and lung cancer, respectively. Pulmonary lesion with alveolar hemorrhage caused by anti-proteinase 3 positive ANCA-associated vasculitis in a patient with acute renal failure $(\mathrm{G})$ and right central type lung cancer with multiple intrapulmonary metastases in another patient admitted for proteinuria $(\mathrm{H})$. 


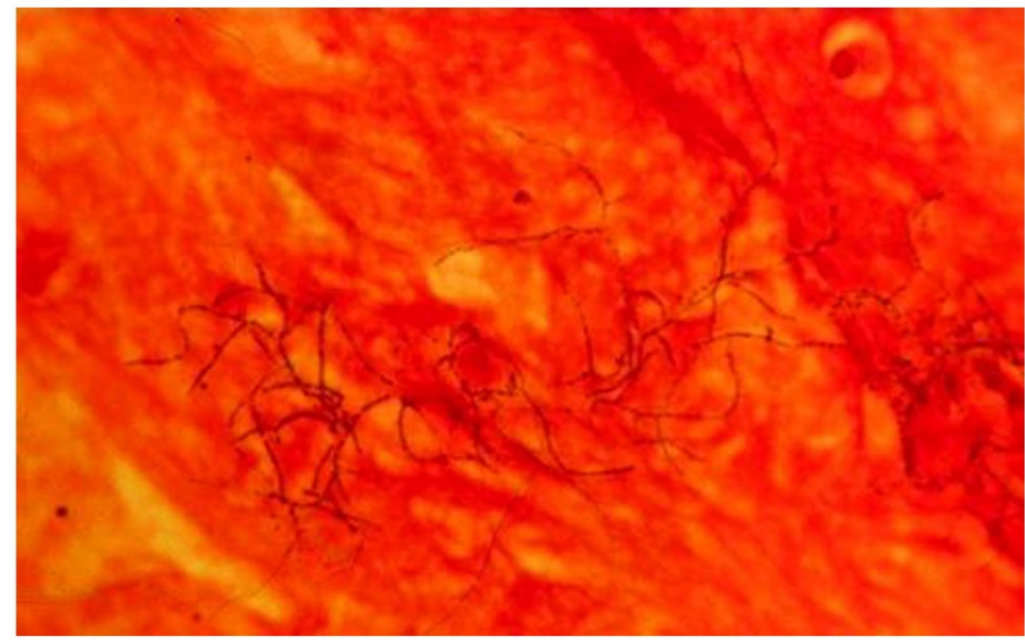

Figure 4. Gram-positive beaded branching filaments of $\boldsymbol{N}$. asteroids in a smear of sputum. Magnification $\times 1,000$. [27]

\section{Nocardial brain abscess}

Cerebral nocardiosis is uncommon, representing only $2 \%$ of all brain abscesses. Nevertheless, the Nocardia spp is known to have a tropism for cerebral tissue [21] and neurological symptoms may include headache, nausea, aphasia and hemiparesis. There are three principal neuroimages on MRI (Figure 2): areas reflecting purulent necrosis; ring lesions consistent with abscess formation following necrosis; and edema originating from vascular exudation and infiltration. Confusingly, cerebral aspergillosis may also mimick similar findings. Facing these ambiguities, Gabelmann et al. did advocate the diagnostic relevance of the G-test and clinical response to specific antifungal treatment [32]. Whenever possible, neurosurgical intervention was recommended [33].

\section{Impaired renal function and increased risk of infection}

Impaired renal function may compromise normal immune function and disturb intestinal barrier [34]. A recent study found that declined renal function did predispose to infections [35] and our latest work confirmed that elevated serum creatinine was an independent risk factor for severe pulmonary infection in nephrotic syndrome patients receiving the cyclosporin regimen [30]. Conversely, the kidneys are known 'victims' of aberrant immune function, which may confer kidney-specific damage-associated molecular patterns that cause sterile inflammation, the development of kidney-targeting autoantibodies and molecular mimicry with microbial pathogens [2]. Conceivably, the risk of nocardial infection may be higher in kidney diseases patients receiving immunosuppression as they are usually accompanied by various degree of renal insufficiency. In this regard, physicians when facing unexplainable hypernatremia should also consider neurogenic origin derived from intracranial infection [36], especially in patients with impaired cell mediated immunity following concurrent pulmonary infection [37].

\section{Specific laboratory tests}

A definite diagnosis is possible with the identification of Nocardia spp in a clinical specimen of a symptomatic patient [20]. The observation of numerous thin branching, filamentous and beaded microorganisms which were Gram-positive and acid-fast is an important indicative of Nocardia spp (Figure 4 and Figure 5) [27]. The incubation time, however, must be unconventionally longer and superimposed infection by Gram-negative bacteria is common [38] (approximately 90 hours and aeruginosa in our case, respectively). Therefore, microbiology laboratory should be informed when nocardiosis is clinically suspected in order to adequately employ the proper growth medium (Loewenstein-Jensen) [39] and decontamination techniques (paraffin baiting) [40]. In contrast, the $16 \mathrm{~S}$ rDNA sequence analysis may greatly speed up this cumbersome process [26]. In order of frequency, the most common pathogenic Nocardia species are N. asteroids, N. brasiliensis and N. Otitidiscaviarum. Others species of Nocardia such as N. farcinica have rarely been isolated from clinical specimens [26].

\section{Unique treatment}

Nocardia asteroids usually show resistance pattern to most antibiotics except trimethoprim/ sulfamethoxazole (TMP/SMX), imipenem and amikacin [41]. A sulfonamide containing regimen, particularly the TMP/SMX, was considered as the treatment of first choice [42,43]. Currently, imipenem used alone or in combination with amikacin was also 


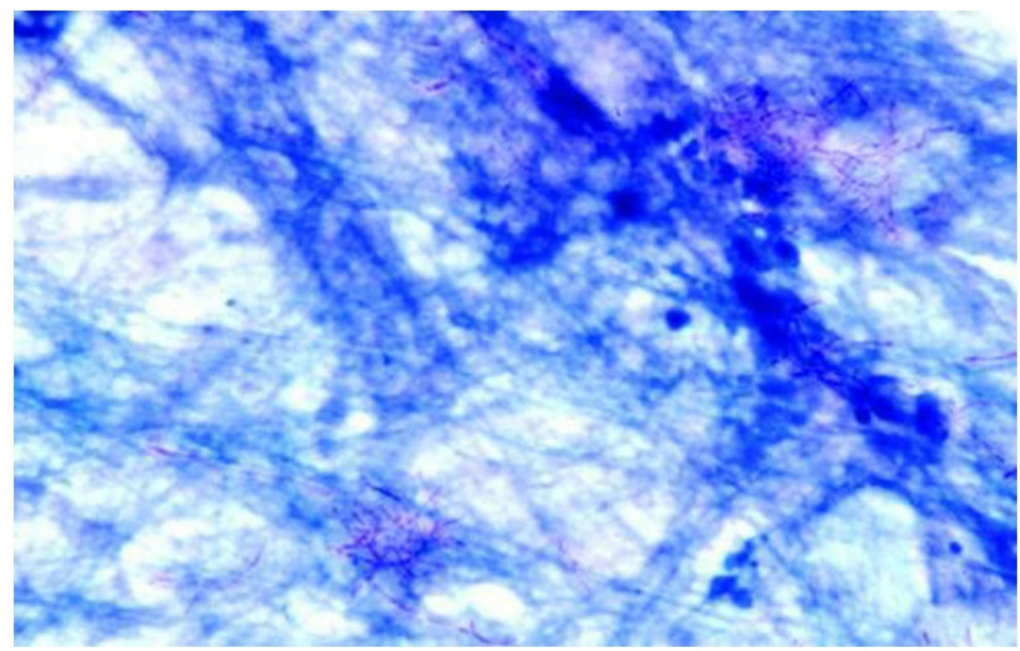

Figure 5. N. asteroides filaments in a direct smear of sputum stained by the modified Kinyoun acid-fast method. Magnification $\times 1,000$ [27]

proposed as a popular therapeutic choice, especially in severely immunocompromised patients, and in cases of central nervous system, disseminated, or advanced infections [21,22]. The optimal duration of treatment, however, is unknown and a prolonged course of medication is mostly recommended because of the relapsing nature of the infection. Of importance, patients with nocardiosis of the central nervous system may benefit from a combined medical-surgical treatment, with a satisfactory clinical outcome [33]. Selection of appropriate antibiotics given at the optimal time is hence crucial for an effective therapy [16]. Nevertheless, empirical treatment should be initiated expediently prior to the results of drug sensitivity test as in most opportunistic infections [44].

\section{Learning Points}

First, rare opportunistic infections are not entirely rare in immunosuppressed patients [45]. Then, hematogenous dissemination of the infection to central nervous system in such patients is not uncommon and diagnostic delay often leads to a fatal outcome [46]. Moreover, spurious laboratory results (such as unexplained hypernatremia) require extra vigilance as they may be the only precursory indicative of an insidious yet progressive disorder [47]. Finally, an effective therapeutic decision clearly depends on multidisciplinary collaboration with the participation of specialists in microbiology and pharmacology [30].

\section{Conclusions}

Our report may share a productive communication between clinicians in general and nephrologists in particular who are caring susceptible patients. Hopefully, these hard-learnt experiences may raise the awareness of this rare yet sometimes lethal infection and enable a successful management.

\section{Acknowledgements}

This study was supported by grants from the Key Research and Development Plan of HeBei Province (18277709D) and HeBei provincial Key Project of Medical Science (20180186).

\section{Competing Interests}

The authors have declared that no competing interest exists.

\section{References}

1. Floege J, Mak RH, Molitoris BA, Remuzzi G, Ronco P. Nephrology research--the past, present and future. Nat Rev Nephrol. 2015; 11: 677-687.

2. Kurts C, Panzer U, Anders HJ, Rees AJ. The immune system and kidney disease: basic concepts and clinical implications. Nat Rev Immunol. 2013; 13: 738-753.

3. Fermand JP, Bridoux F, Kyle RA, Kastritis E, Weiss BM, Cook MA, et al. International Kidney and Monoclonal Gammopathy Research Group. How I treat monoclonal gammopathy of renal significance (MGRS). Blood. 2013; 122: 3583-3590.

4. Vincenti F. Are calcineurin inhibitors-free regimens ready for prime time? Kidney Int. 2012; 82: 1054-1060.

5. Watanabe N, Nakajima H. Coinhibitory molecules in autoimmune diseases. Clin Dev Immunol. 2012; 2012: 269756

6. Zaza G, Tomei P, Granata S, Boschiero L, Lupo A. Monoclonal antibody therapy and renal transplantation: focus on adverse effects. Toxins. (Basel) 2014; 6: 869-891.

7. Tauseef A, Chakraburtty A, Mahmood S, Bronze MS. Risk of nocardial infections with anti-tumor necrosis factor therapy. Am J Med Sci. 2013; 346: 166-168.

8. McNeil MM, Brown JM. The medically important aerobic Actinomycetes: epidemiology and microbiology. Clin Microbiol Rev. 1994; 7: 357-417.

9. Lerner PI. Nocardiosis. Clin Infect Dis. 1996; 22: 891-905.

10. Zhu N, Zhu Y, Wang Y, Dong S. Pulmonary and cutaneous infection caused by Nocardia farcinica in a patient with nephrotic syndrome: A case report. Medicine. (Baltimore) 2017; 96: e7211.

11. Grahammer F, Fischer KG. Pulmonary infiltrate and painful nodular leg lesions in a patient with membranous glomerulonephritis. BMJ Case Rep. 2015. doi: $10.1136 /$ bcr-2015-210032.

12. Elmaci I, Senday D, Silav G, Ekenel F, Balak N, Ayan E, et al. Nocardial cerebral abscess associated with mycetoma, pneumonia, and membranoproliferative glomerulonephritis. J Clin Microbiol. 2007; 45: 2072-2074.

13. Lee JS, Lee YH, Cho SJ, Ji JD, Song GG. A nocardial infection in a patient with systemic lupus erythematosus. Neurology. 2002; 42: 1649-1657.

14. McNab P, Fuentealba C, Ballesteros F, Pacheco D, Alvarez M, Dabanch J, et al. Nocardia asteroides infection in a patient with systemic lupus erythematosus. Rev Med Chil. 2000; 128: 526-528.

15. Ates Ö, Cilan H, Oymak S, Yildiz O, Oymak O. Multidrug-resistant disseminated nocardia farcinica infection in a systemic lupus erythematosus patient. Turk J Rheumatol. 2013; 28: 278-281.

16. Sonesson A, Oqvist B, Hagstam P, Björkman-Burtscher IM, Miörner H, Petersson AC. An immunosuppressed patient with systemic vasculitis suffering from cerebral abscesses due to Nocardia farcinica identified by $16 \mathrm{~S}$ rRNA gene universal PCR. Nephrol Dial Transplant. 2004; 19: 2896-2900.

17. Tilak R, Achra A, Tilak V. Primary cerebral nocardiosis in a renal transplant recipient: a case report. J Clin Diagn Res. 2012; 6: 1417-1418.

18. Weerakkody RM, Palangasinghe DR, Wadanambi S, Wijewikrama ES. "Primary" nocardial brain abscess in a renal transplant patient. BMC Res Notes. 2015; 8: 701.

19. Patel MP, Kute VB, Gumber MR, Shah PR, Patel HV, Dhananjay KL, et al. Successful treatment of Nocardia pneumonia with cytomegalovirus retinitis coinfection in a renal transplant recipient. Int Urol Nephrol. 2013; 45: 581-585.

20. Matulionyte R, Rohner P, Uckay I, Lew D, Garbino JM. Secular trends of nocardial infection over 15 years in a tertiary care hospital. J Clin Pathol. 2004; 57: 807-812.

21. Hui $\mathrm{CH}, \mathrm{Au}$ VWK, Rowland K, Slavotinek JP, Gordon DL. Pulmonary nocardiosis re-visited: experience of 35 patients at diagnosis. Respir Med. 2003; 97: 709-717. 
22. Torres HA, Reddy BT, Raad II, Tarrand J, Bodey GP, Hanna HA, Rolston KV, Kontoyiannis DP. Nocardiosis in cancer patients. Medicine. (Baltimore) 2002; 81: 388-397.

23. Farina C, Boiron P, Ferrari I, Provost F, Goglio A. Report of human nocardiosis in Italy between 1993 and 1997. Eur J Epidemiol. 2001; 17: 1019-1022.

24. Wang T, Zhang Y, Niu K, Wang LJ, Shi YN, Liu B. Association of the -449GC and -1151AC polymorphisms in the DDAH2 gene with asymmetric dimethylarginine and erythropoietin resistance in Chinese patients on maintenance hemodialysis. Clin Exp Pharmacol Physiol. 2017; 44: 961-964.

25. Wang T, Zhang Y, Wang N, Liu Q, Wang ZK, Liu B, et al. Synergistical action of the $\beta 2$ adrenoceptor and fatty acid binding protein 2 polymorphisms on the loss of glomerular filtration rate in Chinese type 2 diabetic nephropathy. Int Urol Nephrol. 2018; 50: 715-723.

26. Kong F, Chen SC, Chen X, Sintchenko V, Halliday C, Cai L, et al. Assignment of reference 5 '-end $16 \mathrm{~S}$ rDNA sequences and species-specific sequence polymorphisms improves species identification of Nocardia. Open Microbiol J. 2009; 3: 97-105.

27. Saubolle MA, Sussland D. Nocardiosis: review of clinical and laboratory experience. J Clin Microbiol. 2003; 41: 4497-4501.

28. Blum U, Windfuhr M, Buitrago-Tellez C, Sigmund G, Herbst EW, Langer M. Invasive pulmonary aspergillosis: MRI, CT, and plain radiographic findings and their contribution for early diagnosis. Chest. 1994; 106: 1156-1161.

29. Martinez F, Chung JH, Digumarthy SR, Kanne JP, Abbott GF, Shepard JA, et al. Common and uncommon manifestations of Wegener granulomatosis at chest CT: radiologic-pathologic correlation. Radiographics. 2012; 32: 51-69.

30. Wang T, Zhang Y, Ping F, Zhao HZ, Yan L, Lin QZ, et al. Predicting risk of pulmonary infection in patients with primary membranous nephropathy on immunosuppressive therapy: the AIM-7C score. Nephrology. in press doi:10.1111/nep.13544.

31. Beaman BL, Ogata SA. Ultrastructural analysis of attachment to and penetration of capillaries in the murine pons, midbrain, thalamus, and hypothalamus by Nocardia asteroides. Infect Immun. 1993; 61: 955-965.

32. Gabelmann A, Klein S, Kern W, Krüger S, Brambs HJ, Rieber-Brambs A, et al. Relevant imaging findings of cerebral aspergillosis on MRI: a retrospective case-based study in immunocompromised patients. Eur J Neurol. 2007; 14: 548-555.

33. Loeffler JM, Bodmer T, Zimmerli W, Leib SL. Nocardial brain abscess: observation of treatment strategies and outcome in Switzerland from 1992 to 1999. Infection. 2001; 29: 337-341.

34. Gandhi BV, Bahadur MM, Dodeja H, Aggrwal V, Thamba A, Mali M. Systemic fungal infections in renal diseases. J Postgrad Med. 2005; 51(Suppl 1): 30-36.

35. Xu H, Gasparini A, Ishigami J, Mzayen K, Su G, Barany P, et al. eGFR and the Risk of Community-Acquired Infections. Clin J Am Soc Nephrol. 2017; 12: 1399-1408.

36. Gonzales M, Marik PE, Khardori RK, O'Brian JT. A pituitary abscess masquerading as recurrent hypernatremia and aseptic meningitis. BMJ Case Rep. 2012; pii: bcr2012006436.

37. Cunha BA. Central nervous system infections in the compromised host: a diagnostic approach. Infect Dis Clin North Am. 2001; 15: 567-590.

38. Kontoyiannis DP, Ruoff K, Hooper DC. Nocardia bacteremia: report of 4 cases and review of the literature. Medicine. (Baltimore) 1998; 77: 2552-2567.

39. Muricy EC, Lemes RA, Bombarda S, Ferrazoli L, Chimara E. Differentiation between Nocardia spp. and Mycobacterium spp.: Critical aspects for bacteriological diagnosis. Rev Inst Med Trop Sao Paulo. 2014; 56: 397-401.

40. Bafghi MF, Heidarieh P, Soori T, Saber S, Meysamie A, Gheitoli K, Habibnia S, Rasouli Nasab M, Eshraghi SS et al. Nocardia isolation from clinical samples with the paraffin baiting technique. Germs. 2015; 5: 12-16.

41. Tripodi MF, Adinolfi LE, Andreana A, Sarnataro G, Durante Mangoni E, Gambardella M, et al. Treatment of pulmonary nocardiosis in heart-transplant patients: importance of susceptibility studies. Clin Transplant. 2001; 15: 415-420.

42. Wilson JP, Turner HR, Kirchner KA, Chapman SW. Nocardial infections in renal transplant recipients. Medicine. (Baltimore) 1989; 68: 38-57.

43. Uttamchandani RB, Daikos GL, Reyes RR, Fischl MA, Dickinson GM, Yamaguchi E, et al. Nocardiosis in 30 patients with advanced human immunodeficiency virus infection: clinical features and outcome. Clin Infect Dis. 1994; 18 : 348-353.

44. Schmitt S, MacIntyre AT, Bleasdale SC, Ritter JT, Nelson SB, Berbari EF, et al. Early infectious diseases specialty intervention is associated with shorter hospital stays and lower readmission rates: a retrospective cohort study. Clin Infect Dis. 2018; doi: 10.1093/cid/ciy494.

45. Rañó A, Agustí C, Sibila O, Torres A. Pulmonary infections in non-HIV-immunocompromised patients. Curr Opin Pulm Med. 2005; 11: 213-217.

46. Massimiliano B, Beretta S, Farina C, Ferrarimi M, Vittorio C. Medical treatment for nocardial abscesses. Case report J Neurol. 2005; 252: 1120-1121.

47. Wang T, Zhang Y, Li QX, Jia SM, Shi CJ, Niu K, et al. Acute kidney injury in cancer patients and impedance cardiography-assisted renal replacement therapy: experience from the onconephrology unit in a Chinese tertiary hospital. Exp Ther Med. 2017; 14: 5671-5677. 